\title{
Experimental and Numerical Investigation on an Integrated Thermal Management System for the Li-Ion Battery Module with Phase Change Material
}

\author{
Qiqiu Huang, ${ }^{1}$ Zhaoda Zhong, ${ }^{1}$ Xinxi Li $\mathbb{D}^{1}{ }^{1}$ Guoqing Zhang, ${ }^{1}$ Dongyang Wei, ${ }^{2}$ \\ Weizhong Yuan, ${ }^{1}$ Jiangyun Zhang, ${ }^{1}$ and Dequan Zhou ${ }^{1}$ \\ ${ }^{1}$ School of Materials and Energy, Guangdong University of Technology, Guangzhou, Guangdong 510006, China \\ ${ }^{2}$ South China Institute of Environmental Sciences, Ministry of Environmental Protection, Guangzhou 510530, China \\ Correspondence should be addressed to Xinxi Li; pkdlxx@163.com
}

Received 5 February 2020; Revised 3 August 2020; Accepted 15 October 2020; Published 9 November 2020

Academic Editor: Zofia Stasicka

Copyright (C) 2020 Qiqiu Huang et al. This is an open access article distributed under the Creative Commons Attribution License, which permits unrestricted use, distribution, and reproduction in any medium, provided the original work is properly cited.

Lightweight power battery modules with outstanding thermal performance are urgently required given the rapid development of electric vehicles. This study proposes a composite phase change material coupled with forced convection as an integrated thermal management system (ITMS) with the aim to control the temperature's rising tendency and maintain the temperature distribution uniformly within an appropriate range among the battery modules. The thermal behavior effects of airflow rates on the thermal management system were investigated in detail by combining experiments and numerical simulations. Comparisons were conducted between an air cooling system with an optimum flow rate and the ITMS. Experimental results revealed that the cooling effect of the ITMS was better than that of the forced cooling system at a $3 \mathrm{~m} / \mathrm{s}$ airflow rate. The maximum temperature in the designed battery module was limited to $63.2^{\circ} \mathrm{C}$. The maximum temperature difference was limited to $4.8^{\circ} \mathrm{C}$ at a $4 \mathrm{C}$ discharge rate. This research indicates that the ITMS is an effective and optimized approach to control and balance the temperature among battery modules, thereby providing engineers with design optimization strategies for similar systems.

\section{Introduction}

Lithium-ion (Li-ion) batteries have been broadly applied in electric vehicles (EVs) owing to their advantages, such as low discharge rate, high capacity, and long lifespan. Heat could be generated during the chemical reaction and ohmic resistance process and lead to temperature rise. However, the performance of Li-ion batteries is easily affected by heat. Hence, the temperature must be controlled within a safe range. A temperature range of $-10^{\circ} \mathrm{C}$ to $50^{\circ} \mathrm{C}$ is generally recognized as a tolerable operating condition; the recommended temperature range for optimal Li-ion battery performance is $20^{\circ} \mathrm{C}-40^{\circ} \mathrm{C}[1-3]$. When heat accumulates to a certain degree inside a battery, the temperature will rapidly rise, and even thermal runaway will occur [4]. The large-scale battery module is restricted by heat dissipation technology in commercial development. Thus, an effective thermal management technology that can guarantee a safe temperature range for battery modules and keep the temperature difference as small as possible must be explored [5].

Many types of battery thermal management systems (BTMS) have been reported in the literature in recent years. The types of BTMS include the air cooling system [6,7], liquid cooling system [8-11], phase change material (PCM) cooling system [12-14], and heat pipe cooling system [15-17]. The air cooling system, which is one of the earliest forms of cooling technology, has supposed to be the simplest and cheapest approach, but its heat transfer coefficient and specific heat capacity of air are much lower than those of the other cooling systems; thus, efficiently dissipating heat and suppressing the temperature difference at a high discharge rate is difficult, especially under certain extreme conditions [18]. Wu et al. [19] conducted experiments and simulations and reported that the heat generated inside the battery pack could not be efficiently dissipated through natural convection cooling. By contrast, 
forced convection can satisfy the requirement for controlling temperature rise for the battery. Park and Jung [20] focused on the arrangement of batteries and parasitic power consumption on the thermal behavior of the air cooling system. The numerical simulation results revealed that a battery module with a small distance for batteries was desirable for the air cooling system. However, the consumed power of the air cooling system for large heat load conditions would become much larger than that of the liquid cooling system for thermal management. An ideal cooling performance of the air cooling system could be obtained by optimizing the design of the heat-dissipating structure. However, a certain degree temperature difference still remains, especially at a high discharge rate.

The liquid cooling system has attracted much attention due to its high cooling efficiency and better temperature uniformity than the air cooling system. With regard to thermal battery management, the liquid cooling system can manage the battery temperature in the module within a normal operating range and maintain the temperature difference within $3^{\circ} \mathrm{C}$ or lower [21]. Vita et al. [22] compared the air and liquid cooling systems, measuring the prismatic Li-ion phosphate battery at different discharge rates under constant current. Irreversible and entropy-based heat generation was also taken into account for mathematical modeling, which was aimed at simulating the temperature evolution and distribution for a battery module. The aforementioned authors further summarized the pros and cons of the two cooling approaches. Huo et al. [23] proposed the cooling system for thermal management of the rectangular Li-ion battery assisted with minichannel cold plates. Various factors, such as flow direction, number of channels, flow rate of coolant mass, and environmental temperature, were investigated in depth by the numerical simulation method. The same research group explored a series of works on the liquid cooling system assisted with minichannel cold plates, which showed a relatively high cooling efficiency $[24,25]$. In spite of the higher cooling effect of the liquid cooling system, several problems, including high cost, leakage, and difficult sustainment, must be overcome.

The PCM, a novel thermal management system in actual application, has received great attention and has been extensively explored due to its simple structure, no power consumption, and high latent capacity [26]. When the battery is discharging, PCM can absorb the generated heat and store it as latent heat. A large portion of heat is utilized during charge, and a small part of it is transferred to the operating environments. When the battery temperature drops below the melting point or is left to shelve, PCM releases the stored heat to the battery module, thus effectively keeping the battery module at a relatively constant temperature and ensuring an excellent temperature difference. Hallaj and Selman [27] investigated the PCM on a battery module and found that the battery temperature was substantially lower and more uniform than the air cooling system at different discharge rates. The PCM cooling system demonstrated many advantages for the battery module, such as effectively prolonging the cycling life [28], decreasing thermal runaway [29], and sustaining a relatively high operating temperature
[30]. Many studies have been conducted to improve the thermal conductivity of BTMS by using various methods, such as adding paraffin (PA) with metal foam/mesh [31-33], metal fins/metallic particle [34], graphene [35, 36], carbon nanotubes [37], and expanded graphite (EG) [38]. Ling et al. [39] found that the factors of the packing density of the composite PCM and mass fraction PA affected the thermal performance. The result verified that the PA/EG composite displayed a small temperature rise rate, proper operating temperature, and uniform temperature distribution for the battery module. The composite PCM with a paraffin density of $890 \mathrm{~kg} / \mathrm{m}^{3}$ and a mass fraction of $75 \%$ could demonstrate optimal thermal management performance. Fathabadi [40] presented a hybrid active-passive system with PA/EG as the composite PCM. The results demonstrated that the temperature rise and difference decrease with the increase in EG mass fraction. Wu et al. [41] designed a 2D thermal model associated with PA/EG composites for battery thermal management. The effects of different EG mass fractions associated with thermal conductivity and different phase change enthalpy were observed at high discharge rates. The investigations revealed that the EG mass fraction of $15 \%-20 \%$ was the optimal proportion to improve the thermal performance of battery modules.

With the increasing heat generation and power of the scale-up battery module, the heat dissipation requirement of batteries for single thermal management has become difficult to achieve. Thus, it is very necessary to apply the integrated thermal management system (ITMS) to address the battery's thermal safety. Several ITMS types, such as the heat pipe cooling/liquid cooling system, PCM/heat pipe cooling system, and air cooling/PCM cooling system, are currently available. $\mathrm{Wu}$ et al. [42] proposed a heat pipe-assisted PCM-based cooling system. The experimental results indicated that the maximum temperature of the battery module could be controlled at less than $50^{\circ} \mathrm{C}$ at a $5 \mathrm{C}$ discharge rate. A low and stable temperature fluctuation could be obtained under several cycling conditions. Jiang et al. [43] designed a tube shell for a battery module with composite PCM coupled with the forced air cooling system. The results indicated that the ITMS could greatly reduce the temperature rise and maintain the temperature difference within $1-2^{\circ} \mathrm{C}$. Lazrak et al. [44] studied PCM by combining ITMS with experiments and simulations, which found that the ITMS could uniformly distribute around the battery and reduce the temperature.

The performance of the battery is sensitive to temperature. Meanwhile, the effectiveness of the BTMS can be greatly improved, especially at high discharge rates. Thus, a feasible and simple thermal management system with multiple cooling approaches for large-scale battery modules should be developed. In this work, an ITMS with PCM coupled with forced air cooling has been proposed for 13 (Series) $* 4$ (Parallel) battery modules composed of 52 cylindrical batteries. By means of coupled air cooling with PCM, the problem of temperature difference in battery modules with air cooling can be effectively solved. At the same time, the PCM has a higher thermal conductivity and greater heat dissipation area, which effectively reduces the external thermal resistance 


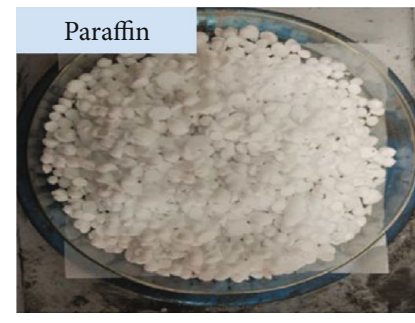

(a)

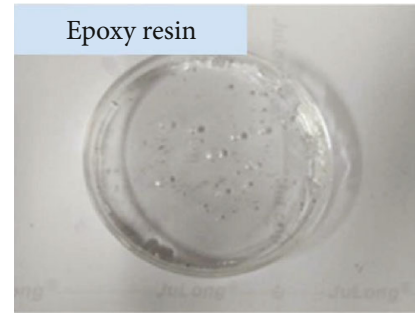

(c)

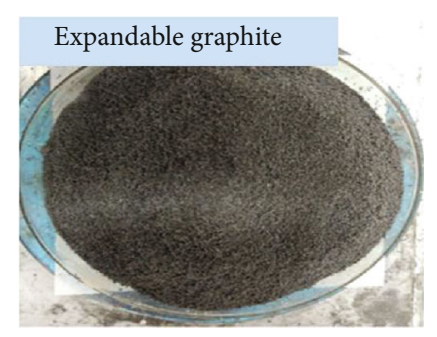

(b)

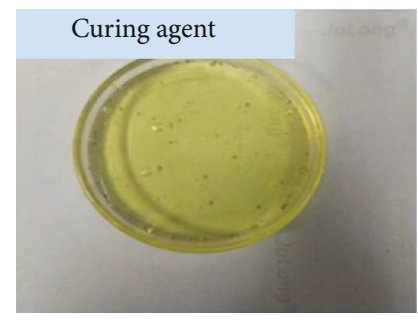

(d)

FIgURE 1: Photograph of the pristine materials prepared for composite PCM: (a) PA, (b) EG, (c) ER, and (d) curing agent.

of the battery module and greatly improves the heat dissipation efficiency of the battery module. Single forced air cooling for batteries was first investigated through experiments and simulations at 1,2 , and $3 \mathrm{~m} / \mathrm{s}$ airflow rates. The ITMS was then used for the battery modules with different current rates. Comparisons between ITMS and forced convection (FC) at the $3 \mathrm{~m} / \mathrm{s}$ airflow rate were analyzed. The designed ITMS could improve the cooling effectiveness of battery modules, especially on a large scale.

\section{Experiment}

In order to study the battery thermal management system with PCM coupled with air cooling, form-stable composite PCM modules were prepared, and then the temperature characteristics of the battery modules with and without PCM were constructed and compared. Finally, experimental data are used to verify the numerical simulation error, so as to improve the accuracy of subsequent experiments.

2.1. Composite PCM Preparation. Figure 1 shows the raw materials for the composite PCM preparation. These materials include paraffin, EG, and epoxy resin (ER). The EG (average particle size: $150 \mu \mathrm{m}$; fixed carbon content: $\geq 99 \%$ ) was obtained from Qingdao Nansha Development Graphite Co., Ltd. Paraffin was purchased from Shanghai Joule Wax Co., Ltd. (carbon content: $\geq 99.99 \%$; melting point: $50^{\circ} \mathrm{C}$; and thermal conductivity: $0.24 \mathrm{~W} /(\mathrm{m} \mathrm{K}))$. ER, a matrix material for enhancing the machinability of the composite PCM, was provided by Hunan Baxiongdi Co., Ltd. The ER (E-44, 6061) and curing agent (molecular weight: 650) mass ratio was $1: 1$.

The expandable graphite was first dried at $60^{\circ} \mathrm{C}$ for $10 \mathrm{~h}$ in a vacuum oven and placed into a muffle furnace. Finally, expandable graphite was subjected to heat treatment at $900^{\circ} \mathrm{C}$ for $7.5 \mathrm{~min}$ to obtain the EG. Predetermined amounts of paraffin were maintained at a constant temperature of $70^{\circ} \mathrm{C}$ for $45 \mathrm{~min}$ in a bath until they completely melted. The paraffin was then mixed with the aforementioned EG under stirring at $2000 \mathrm{rad} \mathrm{min}^{-1}$ for $15 \mathrm{~min}$. Subsequently, ER was added to the mixture under magnetic stirring at $2000 \mathrm{rad}$ $\min ^{-1}$ for $15 \mathrm{~min}$. Curing agent $\mathrm{B}$ was then placed into a mixture, which was continuously stirred at $2500 \mathrm{radmin}^{-1}$ for $5 \mathrm{~min}$. Finally, the obtained PA/EG/ER composite PCM was poured into a preprepared mold and then dried for $24 \mathrm{~h}$ at a constant temperature of $80^{\circ} \mathrm{C}$. The determination of the PCM amount is related to the thermal conductivity, specific heat capacity, heat production, and other thermophysical parameters of the battery module. The heat generation rate of the battery module at a $4 \mathrm{C}$ discharge rate must be determined to calculate the quality required by PCM. The mass proportions of paraffin, EG, and ER were $50 \%, 3 \%$, and $47 \%$, respectively. The melting point and latent heat of the composite PCM were measured with a differential scanning calorimeter (DSC2910, Texas Instruments Inc., USA) in an $\mathrm{N}_{2}$ atmosphere. The thermal conductivity was measured using an LFA447 NanoFlash ${ }^{\mathrm{TM}}$ system (range: 0.1-2000 W/(m K); accuracy: $\pm 5 \%$; and repeatability: $\pm 3 \%)$.

2.2. Assembly Description of Battery Modules. Figure 2 displays the detailed assembly processing and the specific design schemes of the battery modules. The PCM block was fashioned through a milling machine to acquire a smoothsurface and standard-dimension PCM block consisting of 52 uniformly distributed holes (Figures 2(a) and 2(b)). Thereafter, the commercial cylindrical 18650 batteries with outstanding electrical-chemical properties consistent with the arranged thermocouples were inserted into the PCM heat dissipation skeleton. The electrical connection was then established with a mash welder with $35 \mathrm{~W}$ input power and 15 A working current to avoid unsuccessful welding. Two pairs of Ni sheets were utilized to connect the adjacent batteries to avoid damage from high charge-discharge current or high temperature on the power batteries (Figure 2(c)). After the electrical connection was completed, a multimeter was employed to measure the voltage of every string and confirm 


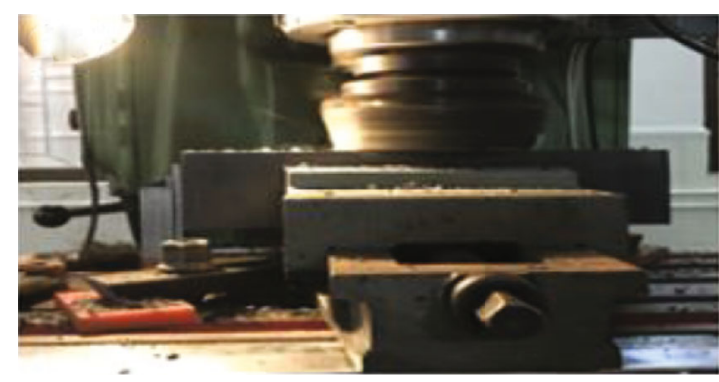

(a)

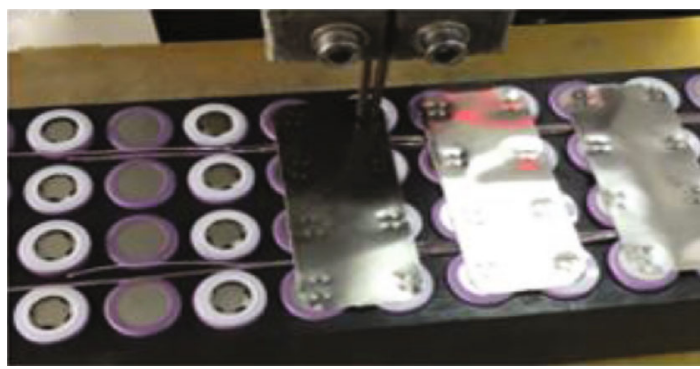

(c)

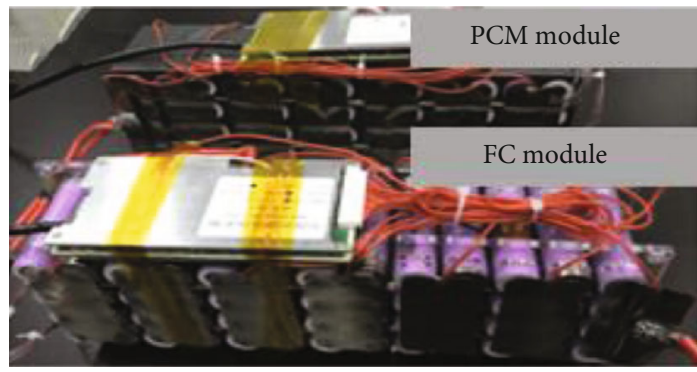

(e)

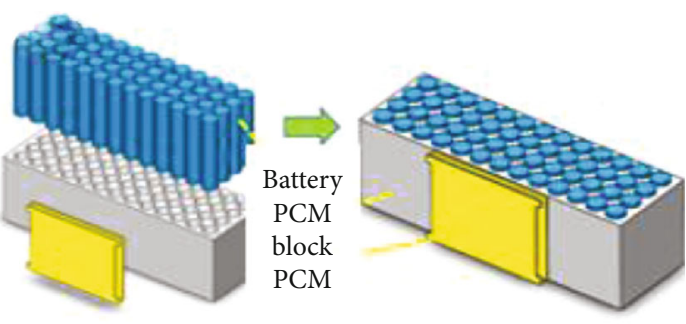

(g)

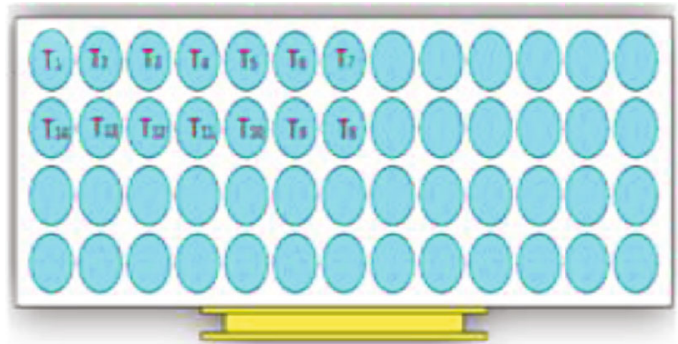

(i)

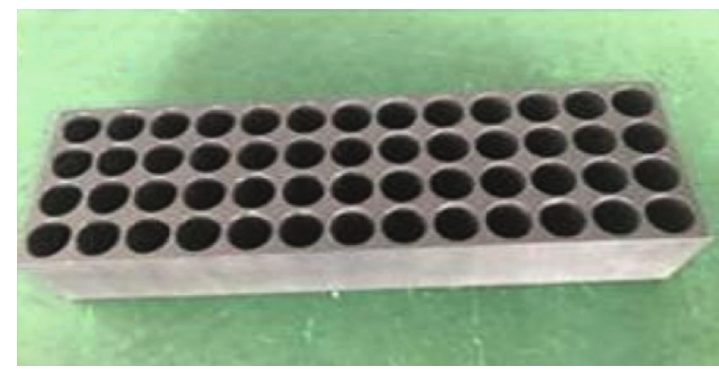

(b)

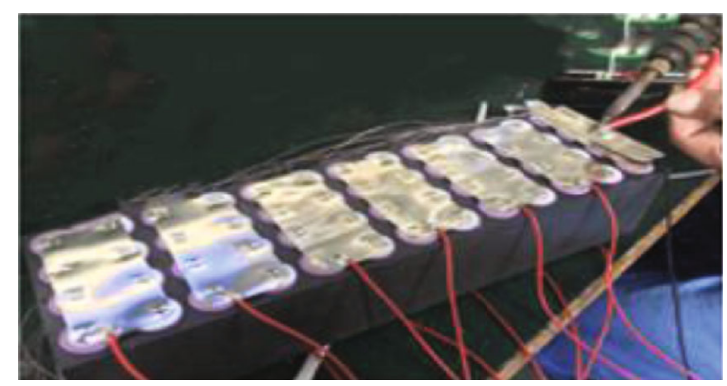

(d)

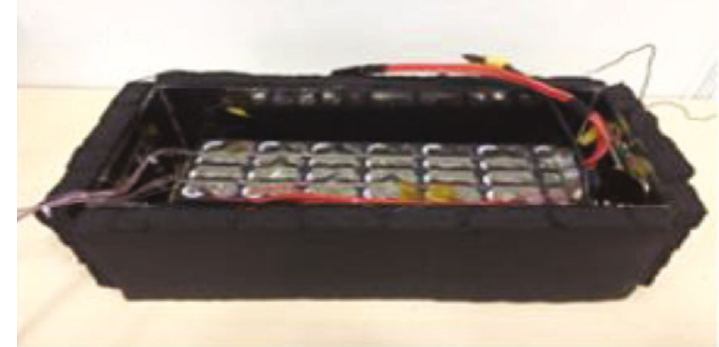

(f)

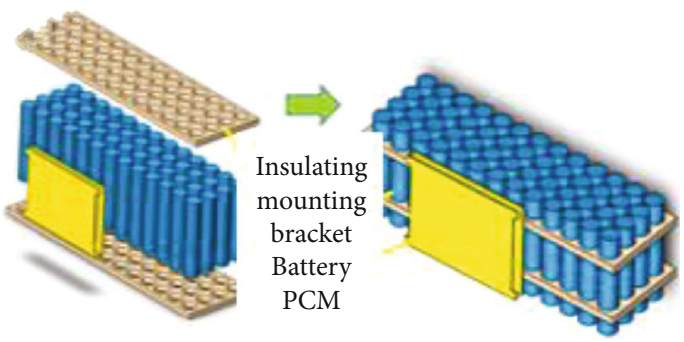

(h)

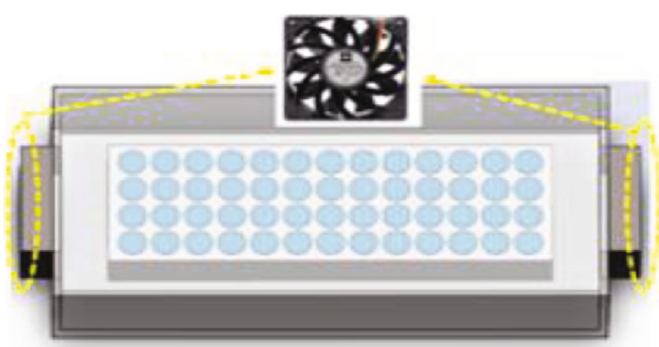

(j)

Figure 2: Schemes of the assembly process of the power battery modules and the specific design schemes.

the validity and accuracy during the PCM installation process (Figure 2(d)). Generally, PCM was aimed at providing an effective circuit protection system and restraining over- charge, overdischarge, and overcurrent. Figure 2(e) exhibits the accomplished traditional forced air cooling module without the participation of the PCM heat dissipation medium 
TABLE 1: Parameters of the battery module.

\begin{tabular}{lc}
\hline Property & Parameter \\
\hline Size $(\mathrm{mm})$ & $276 \times 88 \times 65$ \\
Spacing between batteries $(\mathrm{mm})$ & 2.5 \\
Hole diameter $(\mathrm{mm})$ & 18.5 \\
Mass of PCM block $(\mathrm{g})$ & 582.4 \\
Discharge cutoff voltage $(\mathrm{V})$ & 36.4 \\
Overcharge protection voltage $(\mathrm{V})$ & 55.2 \\
Maximum discharge current $(\mathrm{A})$ & 35.2 \\
\hline
\end{tabular}

and power battery module. For practical application, the size of the battery module is limited, and the thickness of the PCM cannot be too thick. Generally, the thickness of the PCM is $3 \mathrm{~mm}$, which can ensure that the PCM module is not easy to break during the milling machine. The modules were encapsulated in an acrylic shell with a $3 \mathrm{~mm}$ thick layer of insulation materials for the subsequent experimental testing and evaluation (Figure 2(f)). Figure 2(h) describes the design details of the single battery module without PCM. One-quarter of the battery module was used as the submodule to investigate the heat dissipation performance in detail according to the symmetry principle with 14 T-type thermocouples attached in the middle of the battery's outer surface (Figure 2(i)). Figure 2(j) shows the battery module of PCM coupled with FC for thermal management and two fans on the two sides of the shells [45].

The $46.8 \mathrm{~V} / 8.8 \mathrm{Ah} \mathrm{LiNiCoMnO}_{2}$ battery modules containing 52 commercial cylindrical 18650 batteries with $13 S *$ $4 \mathrm{P}$ purchased from Hubei O'CELL Energy Co., Ltd., were studied. The composite PCM properties were as follows: latent heat of $146.2 \mathrm{~kJ} / \mathrm{kg}$, specific heat capacity of $2300 \mathrm{~J} /(\mathrm{kg} \mathrm{K})$, density of $940 \mathrm{~kg} / \mathrm{m}^{3}$, thermal conductivity of $1.35 \mathrm{~W} /(\mathrm{m} \mathrm{K})$, and phase change temperature of $44.0^{\circ} \mathrm{C}-$ $48.2^{\circ} \mathrm{C}$. Table 1 illustrates the parameters of the battery module used in this study.

2.3. Experimental Setup. Figure 3 displays a schematic of the experimental system. A battery testing system (BTS50V120A-NTF, Shenzhen Neware Electronics Co., Ltd., China) was used to conduct the charge and discharge tests for the battery modules. T-type thermocouples (OMEGA type TT-T-30-SLE-1M) were installed on the middle surface of each battery to record the temperature data by using a PC-based data acquisition unit (Agilent 34970A) with $1 \mathrm{~s}$ interval. All thermocouples were calibrated with a standard thermometer within the temperature range of $0-100^{\circ} \mathrm{C}$. The airflow rates of the FC module were controlled and measured by a DC power supply (YK-AD12015, Yucoo Network Equipment Co., Ltd.) and anemograph (GM816A, Shenzhen BENETECH Instrument Co., Ltd.), respectively. The battery modules were placed in the thermostat (BTH800, Dongguan GBELL Co., Ltd., China) for constant temperature treatment. The temperature range of the thermostat is from $-40^{\circ} \mathrm{C}$ to $150^{\circ} \mathrm{C}$, and its temperature departure is $\leq \pm 2^{\circ} \mathrm{C}$. The heating and cooling rates are 3 and $1^{\circ} \mathrm{C} \mathrm{min}^{-1}$, respectively.
2.4. Measurement of Battery Modules. The ITMS and FC cooling system were tested at $25^{\circ} \mathrm{C}$. During the experiments, the battery modules obeyed the following charge protocols: $1 \mathrm{C}$ charge rate with a voltage cutoff limit of $54.6 \mathrm{~V}$ in galvanostatic mode until the current dropped to the cutoff limit $0.5 \mathrm{~A}$ in potentiostatic mode. The allotted equilibration time was at least $1 \mathrm{~h}$ after the charging process. Subsequently, the battery modules were discharged at rates of $1,2,3$, and $4 \mathrm{C}$.

\subsection{Simulated Model and Solution}

2.5.1. Governing Equations. The conjugate heat transfer problem in this research was solved by using COMSOL Multiphysics 5.2a.

The energy conservation of the battery is expressed as follows:

$$
\rho C_{\mathrm{p}} \frac{\partial T}{\partial t}=\frac{\partial}{\partial x}\left(k \frac{\partial T}{\partial y}\right)+\frac{\partial}{\partial y}\left(k \frac{\partial T}{\partial y}\right)+\frac{\partial}{\partial z}\left(k \frac{\partial T}{\partial z}\right)+Q,
$$

where $k$ is the thermal conductive coefficient; and $\rho$ and $C_{\mathrm{p}}$ represent the average density and specific heat of the battery, respectively. $Q$ is the heat generated by unit battery. This equation provides the basic tool for heat conduction analysis, and from its solution, the temperature distribution of the battery can be obtained as a function of time.

The energy conservation of air is given as follows:

$$
\left(\frac{\partial}{\partial t}+\nabla \vec{v}\right)\left(\rho_{\mathrm{a}} C_{\mathrm{p}, \mathrm{a}} T_{\mathrm{a}}\right)=\nabla\left(k_{\mathrm{a}} \nabla T_{\mathrm{a}}\right),
$$

where $\nabla \vec{v}$ presents the velocity vector, $C_{\mathrm{p}, \mathrm{a}}$ is the specific heat of the air, $\rho_{\mathrm{a}}$ is the density, $T_{\mathrm{a}}$ is the temperature, and $k_{\mathrm{a}}$ is the thermal conductive coefficient of air.

The continuity equation for air is written as follows:

$$
\rho_{\mathrm{a}}\left(\frac{\partial}{\partial t}+\nabla \vec{v}\right)=0 .
$$

The momentum conservation equation for air is expressed as follows:

$$
\rho_{\mathrm{a}}\left(\frac{\partial \nabla \vec{v}}{\partial t}+(\nabla \vec{v}) \vec{v}\right)=\nabla P+\mu \nabla^{2} \vec{v},
$$

where $\mu$ represents the dynamic viscosity of air and $P$ represents the static pressure.

2.5.2. Boundary Conditions and the Grid Independence Test. The boundary conditions of the outlet and inlet were set as the pressure outlet and velocity inlet. No slip boundary was used for the inside surface of the channels. The inlet air temperature was set to $25^{\circ} \mathrm{C}$, which was equal to the ambient temperature. Table 2 shows the parameters of the material properties used in the simulation.

The grid independence test is essential to ensure the calculation accuracy of the simulation. A grid number of 1204654 is chosen. Figure 4 illustrates the test result. The 


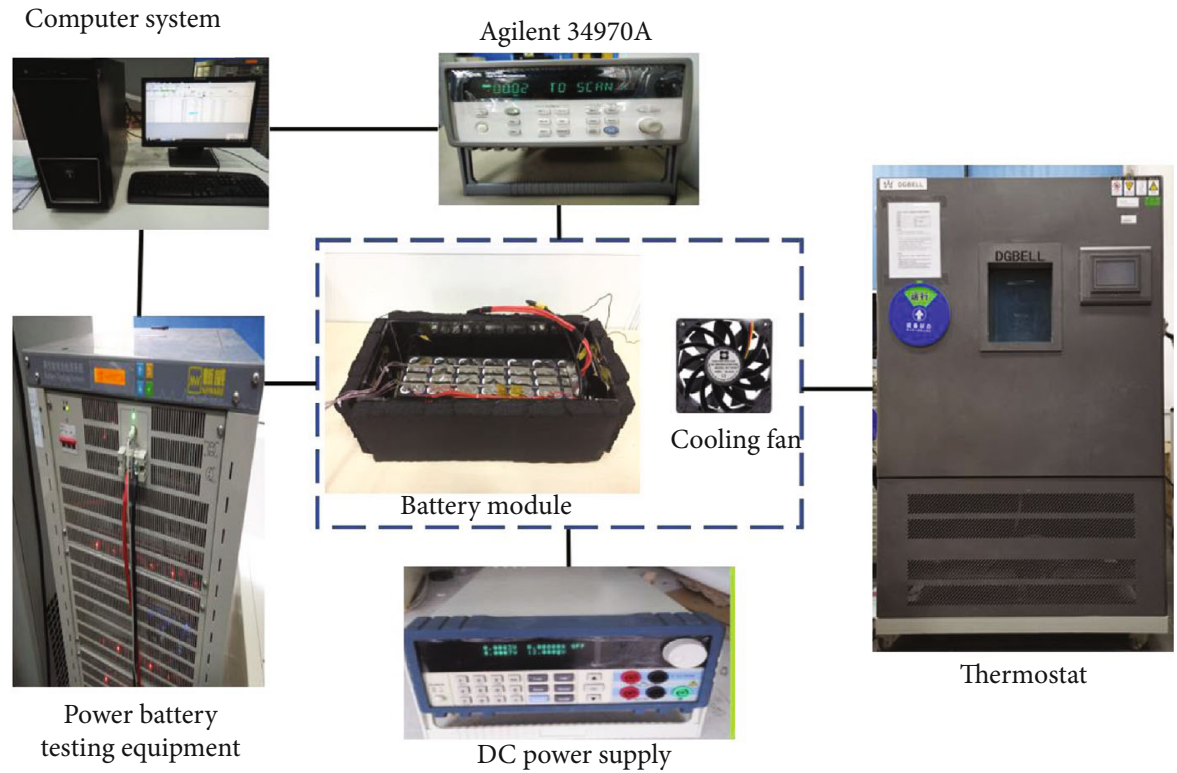

FIGURE 3: Schematic of the experimental system.

TABLE 2: Material properties used in the simulation.

\begin{tabular}{lcccc}
\hline Material & $\rho\left(\mathrm{kg} / \mathrm{m}^{3}\right)$ & $C_{\mathrm{p}}(\mathrm{J} /(\mathrm{kg} \mathrm{K}))$ & $k(\mathrm{~W} /(\mathrm{m} \mathrm{K}))$ & $\mu\left(\mathrm{Pa} \mathrm{s}^{-1}\right)$ \\
\hline Battery & 2450.52 & 1625 & 3.42 & - \\
Air & 1.185 & 1.005 & 0.0263 & $1.835 \times 10^{-5}$
\end{tabular}

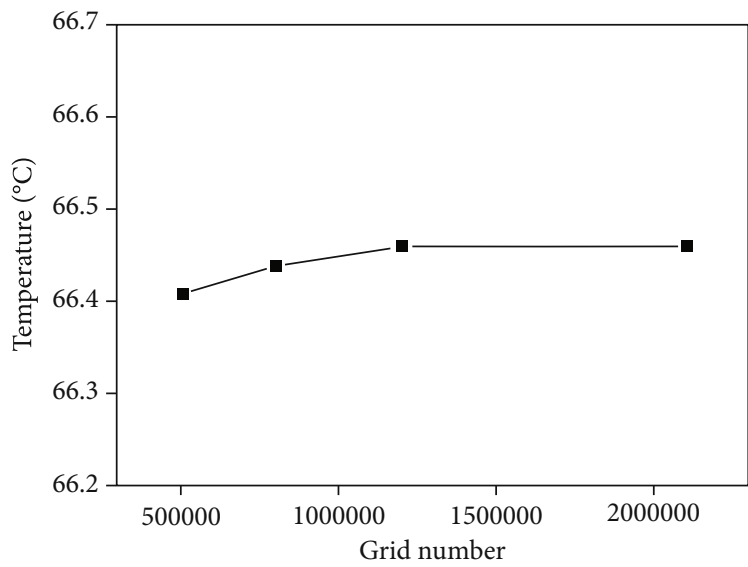

FIGURE 4: Independence test of the grid number.

temperature of the middle surface of the single 18650 cylindrical battery in $600 \mathrm{~s}$ at a $4 \mathrm{C}$ discharge rate was utilized to calculate the independence of the grid number. A single battery with insulation cotton packaging was tested at a constant discharge rate of $4 \mathrm{C}$ to obtain the thermal behavior and heat generation through the experimental platform (Figure 3).

The batteries with thermocouples were placed in the middle of the outer surface. The following charge-discharge operations were conducted: a $1 \mathrm{C}$ charge rate with a voltage

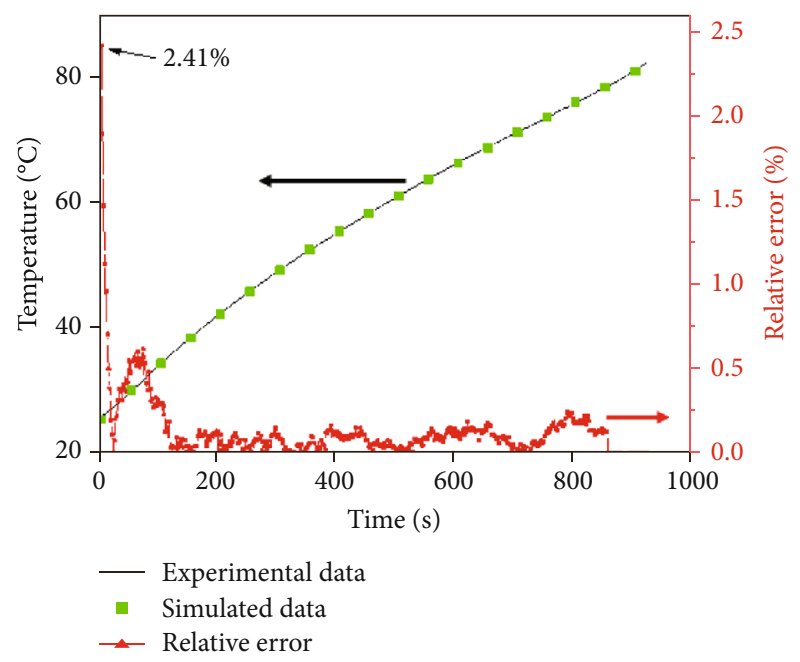

Figure 5: Comparison of the experimental and simulated results of a single battery.

cutoff limit of $4.2 \mathrm{~V}$ in galvanostatic mode was used until the current dropped to the cutoff limit $0.5 \mathrm{~A}$ in potentiostatic mode. The battery was discharged at a $4 \mathrm{C}$ discharge rate until the voltage decreased to $2.8 \mathrm{~V}$. Figure 5 presents the comparison between the simulation and experimental results. The relative error did not exceed $2.4 \%$. The simulated results were in agreement with the experimental data, thereby indicating that the battery heat generation in simulations is reasonable [46]. By setting the battery in an adiabatic environment for discharging at different rates, the data of temperature change was collected, and the corresponding calorific value of the battery was calculated according to the formula. In the process of charging and discharging, the lithium-ion battery has four forms of heat generation, mainly 

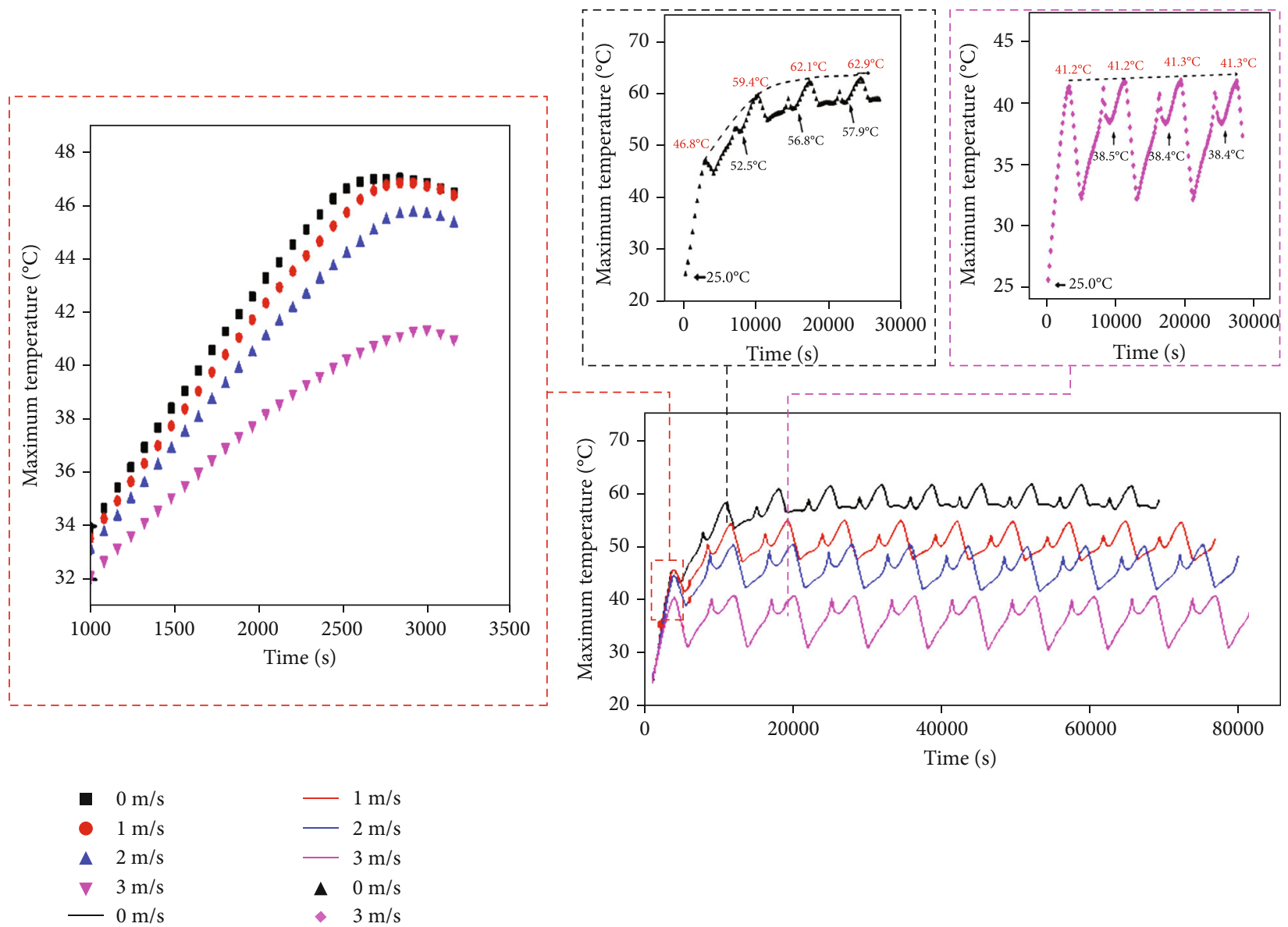

FIGURE 6: Temperature variations of the FC module with different forced airflow rates during the cycle process (1 C).

including the following: reaction heat $Q_{\mathrm{r}}$, polarization reaction heat $Q_{\mathrm{p}}$, side reaction heat $Q_{\mathrm{s}}$, and Joule heat $Q_{\mathrm{j}}$. Total heat generation can be expressed by the following formula:

$$
Q=Q_{r}+Q_{s}+Q_{p}+Q_{j}
$$

The average heat generation rate is expressed as follows:

$$
q=\frac{Q}{t}
$$

where $t$ is the working time of the discharging process, $Q$ is the total heat generation by the battery, and $q$ is the average heat generation rate of the battery.

The heat generation rates of the battery were 23.37 and $218.95 \mathrm{~W}$ at 1 and $4 \mathrm{C}$ discharge rates, respectively, according to the calculated internal heat source in the adiabatic environment.

\section{Results and Discussion}

In this section, the ITMS and FC cooling system for the largescale battery module were discussed and analyzed in detail. First, the large-scale battery modules with the FC cooling system with various parameters, such as the airflow rate and discharge rate, were investigated through experiments and simulations. The numerical simulation and experimental results are in agreement. The comparison between the ITMS and the FC cooling system for decreasing the maximum temperature and balancing the temperature difference is researched.

\subsection{Heat Dissipation Evaluation during the Charge-Discharge} Cycle Process. In actual driving operations, the running status of power batteries always changes with the practical road condition. The influence of airflow rates on the heat dissipation performance of the as-prepared FC cooling system during cycling was investigated in detail. Figure 6 exhibits that the maximum temperature gradually increased with the increase in the charge-discharge experiment. The thermal energy heat for the first discharging process was stored in the battery module. If the absorbed heat generated by the battery module cannot be dissipated promptly to the environment due to the low heat transfer efficiency, then the battery module will be exposed to a high temperature and exhibit a rising preliminary temperature during the following cycles. Consequently, the initial temperatures of the abovementioned FC cooling system with a $0 \mathrm{~m} / \mathrm{s}$ airflow rate reached $46.8^{\circ} \mathrm{C}, 59.4^{\circ} \mathrm{C}, 62.1^{\circ} \mathrm{C}$, and $62.9^{\circ} \mathrm{C}$ in the first, second, third, and fourth cycles, respectively, thereby increasing the maximum temperature for each discharging process. Hence, the battery module with a $0 \mathrm{~m} / \mathrm{s}$ airflow rate could 


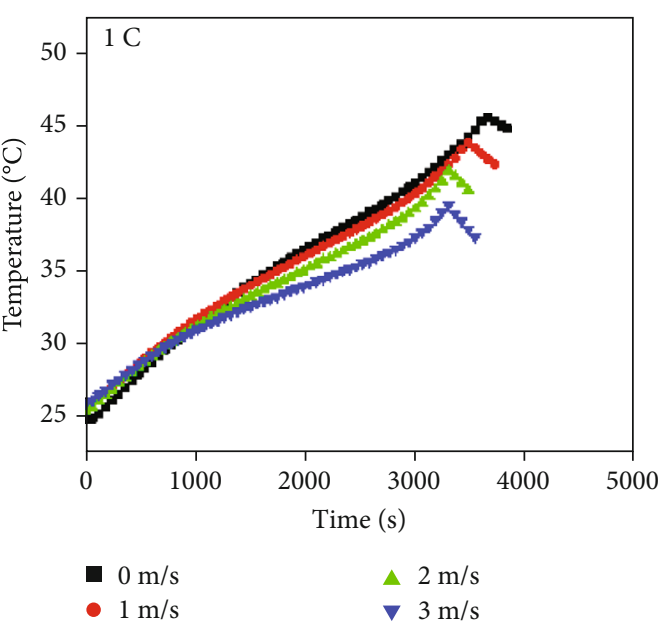

(a)

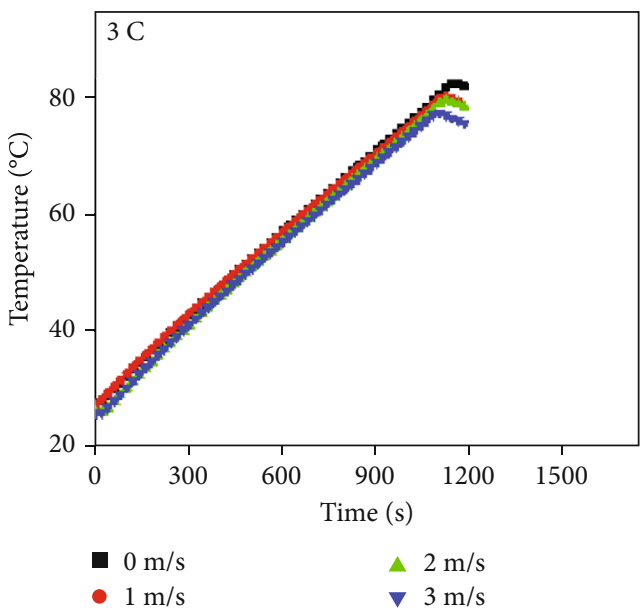

(c)

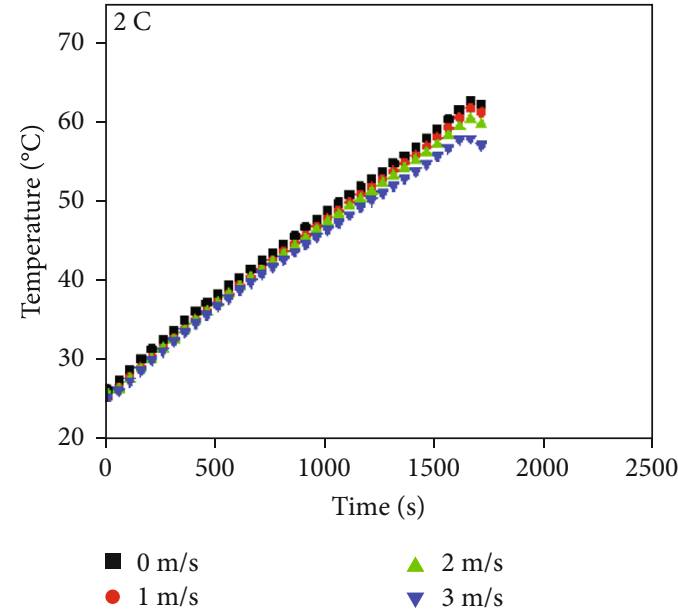

(b)

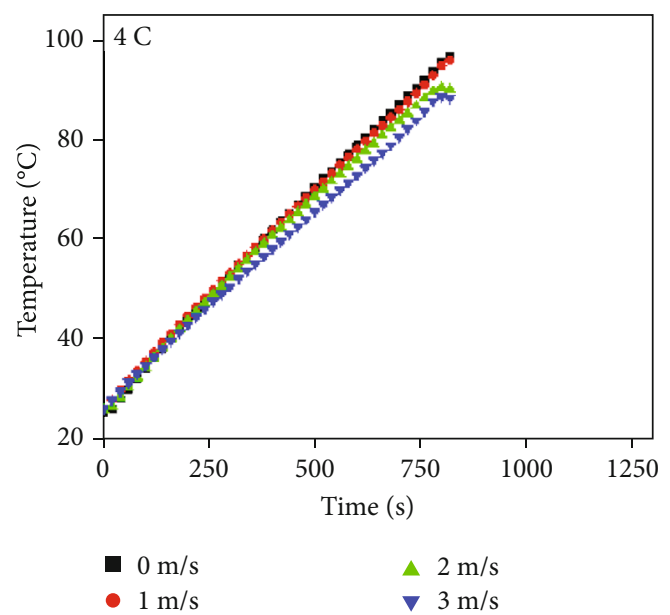

(d)

FIGURE 7: Temperature comparison of the battery modules with various airflow rates at different discharge rates.

not be controlled within the suitable temperature range. Considering the demand for heat dissipation performance, high airflow rates of 1,2 , and $3 \mathrm{~m} / \mathrm{s}$ were applied in the FC cooling system. The results indicated that the stable initial and maximum temperatures were maintained at approximately $46.6^{\circ} \mathrm{C}, 45.6^{\circ} \mathrm{C}$, and $41.4^{\circ} \mathrm{C}$ accompanied with 1,2 , and $3 \mathrm{~m} / \mathrm{s}$, thereby showing enhanced heat transfer efficiency.

At the airflow rate of $3 \mathrm{~m} / \mathrm{s}$ for the battery module, the temperature at the beginning of the first, second, third, and fourth cycles reached $41.2^{\circ} \mathrm{C}, 41.2^{\circ} \mathrm{C}, 41.3^{\circ} \mathrm{C}$, and $41.3^{\circ} \mathrm{C}$, respectively, thereby indicating that the temperature range decreased with time and was always within the safe operating temperature range of the power battery. The test results of the FC cooling system with 1 and $2 \mathrm{~m} / \mathrm{s}$ showed a similar change trend. These results indicate that FC could benefit the thermal management and thermal safety performance of the battery module.

The thermal management system with FC can increase the heat dissipation rate of the battery module and reduce the maximum temperature of the battery. With the increase in wind speed, the cooling effect is further optimized. However, for large-scale modules, the wind speed needs to reach
$3 \mathrm{~m} / \mathrm{s}$ in order to present a relatively obvious cooling efficiency.

3.2. Temperature Responses of the Battery Modules at Different Discharge Rates. Figure 7(a) illustrates that when the discharge rate was $1 \mathrm{C}$, the peak temperature of the $\mathrm{FC}$ cooling system reached $45.7,43.9,41.9$, and $39.6^{\circ} \mathrm{C}$ at 0,1 , 2 , and $3 \mathrm{~m} / \mathrm{s}$, respectively. The peak temperature $(3 \mathrm{~m} / \mathrm{s})$ of the FC cooling system decreased by $15.4 \%$ compared with that of the FC cooling system $(0 \mathrm{~m} / \mathrm{s})$ under the same ambient temperature condition. When the airflow rate was $0 \mathrm{~m} / \mathrm{s}$, no air disturbance was observed outside the battery module, except the natural convection heat transfer by air. At this time, the convection heat transfer coefficient was small, which cannot eliminate the heat on the battery surface in a timely manner. Consequently, the battery module temperature was high. The air disturbance around the battery became increasingly strong with the airflow increase. At this time, the battery module surface underwent intense convection heat transfer. The convection heat transfer coefficient was large, and the heat removed by the disturbed air increased, resulting in the low temperature of the battery module. This 


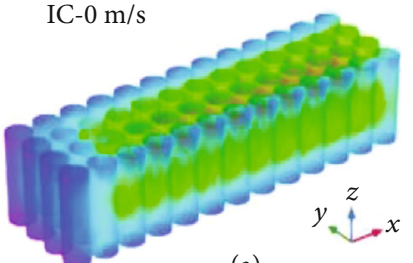

(a)

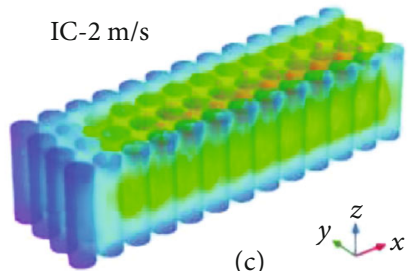

(c)
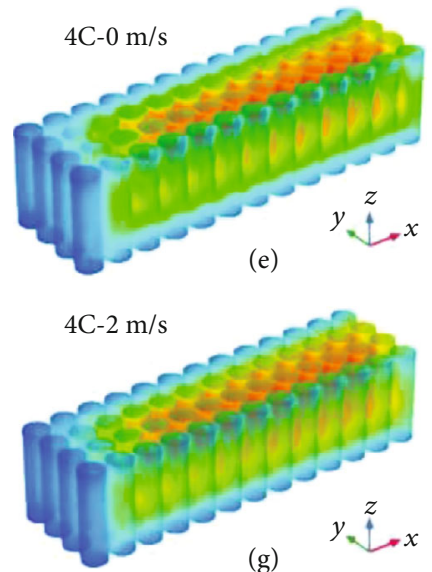

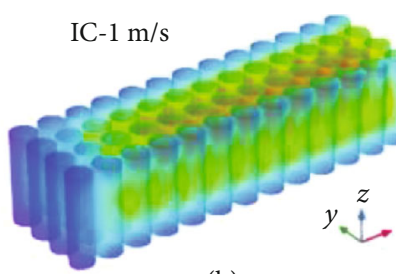

(b)

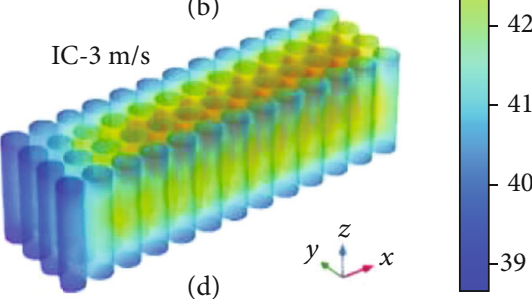

(d)

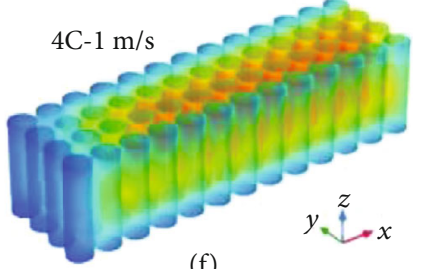

(f)

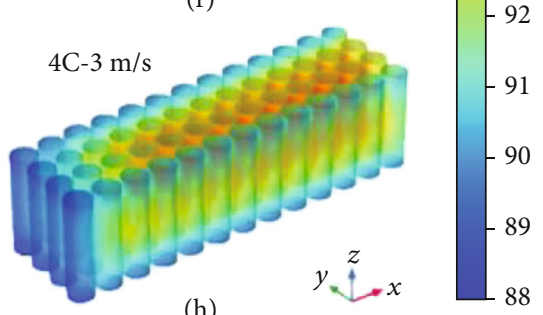

(h)

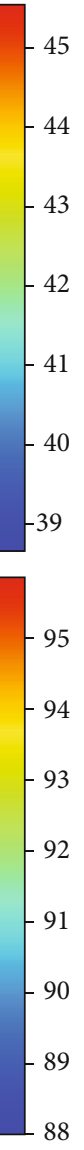

45 4 43 (1) (1)

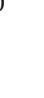

Figure 8: Temperature distribution nephogram of the battery module. finding indicates the outstanding controlling temperature capacity and heat dissipation effect. The same tendency was observed at 2, 3 , and $4 \mathrm{C}$ discharge rates.

The same conclusions could be verified through the numerical simulations (Figure 8 ). The heat dissipation performance of the FC cooling system with a $3 \mathrm{~m} / \mathrm{s}$ airflow rate was superior to that of the other three operating conditions.

The conventional discharge current is applied when the power battery module is used under normal working conditions. At this time, the heat generated by the battery module is small. We can see the law through the simulation diagram. However, the battery module will discharge at a high rate when the power battery module for EV works under extreme conditions, such as climbing hills and accelerating. Consequently, the overall temperature of the battery module becomes much higher than that of the conventional discharge rate. Figures $8(a)-8(d)$ demonstrate that the maximum temperatures at a $1 \mathrm{C}$ discharge rate were $45.5^{\circ} \mathrm{C}$, $43.1^{\circ} \mathrm{C}, 42.4^{\circ} \mathrm{C}$, and $39.2^{\circ} \mathrm{C}$ at $0,1,2$, and $3 \mathrm{~m} / \mathrm{s}$, respectively. Figures $8(\mathrm{e})-8(\mathrm{~h})$ show that the maximum temperature at a $4 \mathrm{C}$ discharge rate was $95.5^{\circ} \mathrm{C}, 94.7^{\circ} \mathrm{C}, 91.4^{\circ} \mathrm{C}$, and $89.7^{\circ} \mathrm{C}$ at $0,1,2$, and $3 \mathrm{~m} / \mathrm{s}$, respectively. This finding shows a declining trend with the increased airflow rate. The peak temperature can be measured in the battery's middle position, whereas the temperature of the FC cooling system was higher than that on the central surface of the battery. In comparison with $0 \mathrm{~m} / \mathrm{s}$, the $3 \mathrm{~m} / \mathrm{s}$ airflow rate shows a decrease of $6.3^{\circ} \mathrm{C}$ and $5.8^{\circ} \mathrm{C}$ at 1 and $4 \mathrm{C}$ discharge rates, respectively. The cooling effect worsens with the discharge rate increase because of the heat that accumulated in the center of the module. Such heat cannot easily dissipate to ambient surroundings quickly and in a timely manner. The forced air convection cooling method with a high airflow rate had a thermal management effect, but it is always accompanied with high installation and maintenance costs. Hence, the FC cooling system scheme is not the optimum choice at high discharge rates.

When the battery module is discharged at a low rate, the FC cooling system provides a stable cooling effect. However, when the battery heat generation rate increases, the air cooling cannot effectively cool the entire battery module. Severe heat accumulation occurs inside the battery module, which reduces the temperature consistency of the battery module.

3.3. Mechanical Property Analysis. Figure 9 presents the relationship among shock, bending, and tensile strength with the increase in the PA content for the as-prepared composite PCM. We tested the different components of PCM and found that the overall mechanical properties of PCM showed a declining trend when the PA content increases within a certain range. The PCM mechanical properties were optimal overall when the PA content was $50 \%$, which is conducive to the practical application of PCM. The main reasons for the aforementioned phenomenon are as follows: (1) the participation of the increased amount of low molecular paraffin 

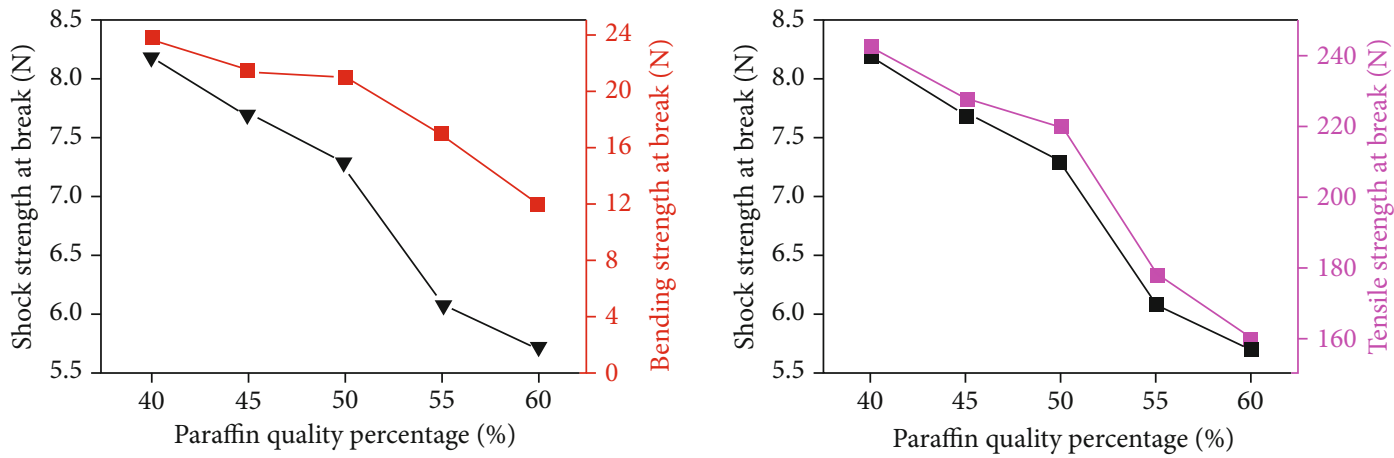

FIGURE 9: Bending and tensile strength break at different proportions of paraffin.
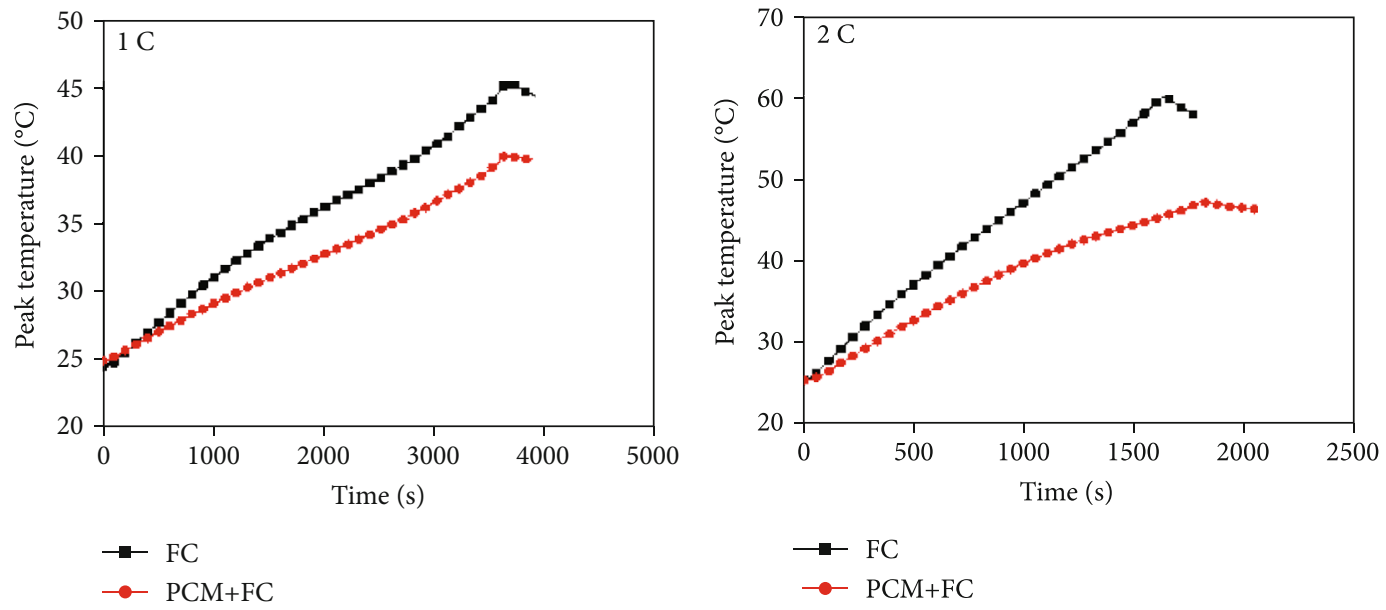

(a)

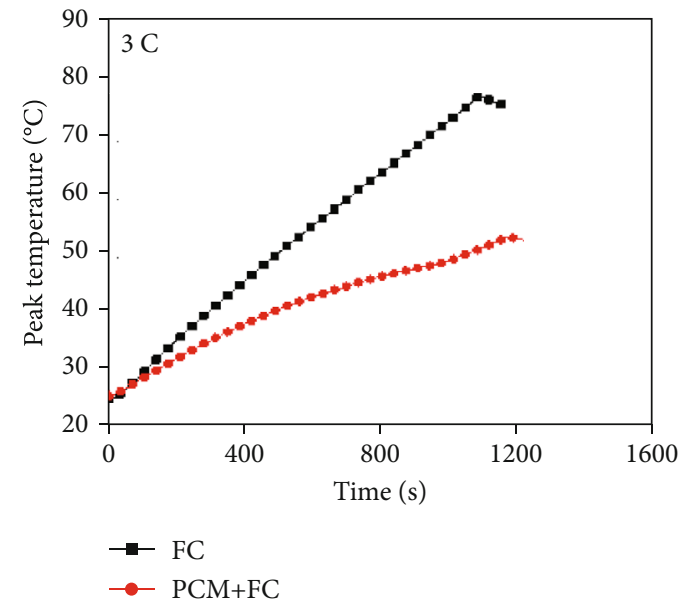

(c)

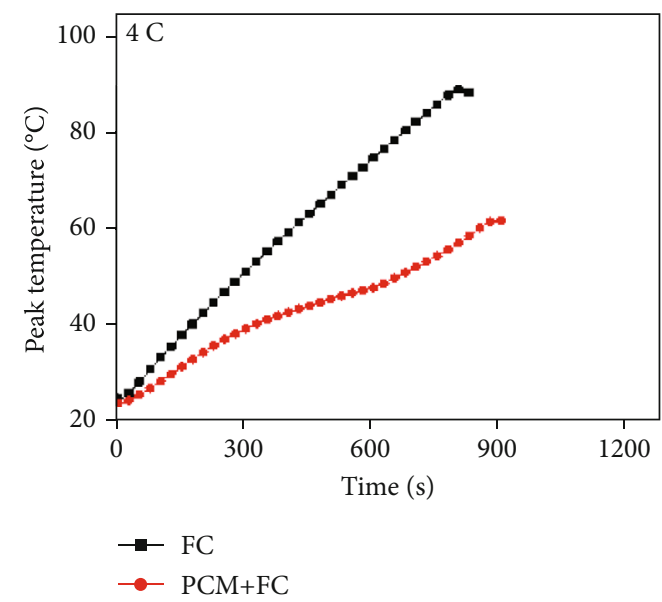

(d)

FIGURE 10: Peak temperature comparisons of the battery modules with the FC cooling system and PCM coupled with the FC cooling system $(3 \mathrm{~m} / \mathrm{s})$.

decreased the mechanical strength of the composite PCM; (2) the decrease in ER further resulted in the destruction of the crosslinked network structure.

The increase in paraffin content could cause a decline in the abovementioned mechanical properties among these composite PCM. This phenomenon should be recognized as the crystals of the paraffin acting as the propagation of stress cracking and defect points for the initiation. The curve of shock strength was slight, which was different from the bending and tensile strength, while the paraffin ratio was greater than $50 \%$. This condition could be attributed to the 3D network structure of the composite PCM with $47 \%$ mass ratio epoxy, which can surround the paraffin and create a compact crosslinked structure throughout the composite 


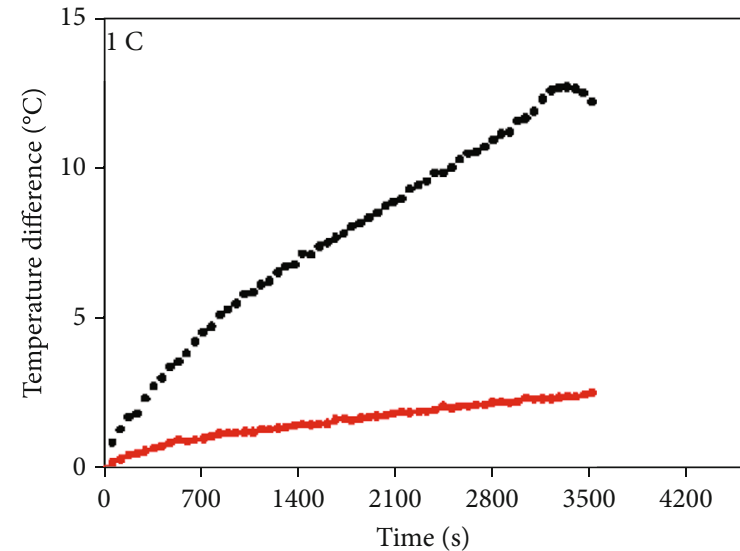

- $\mathrm{FC}$

- $\mathrm{PCM}+\mathrm{FC}$

(a)

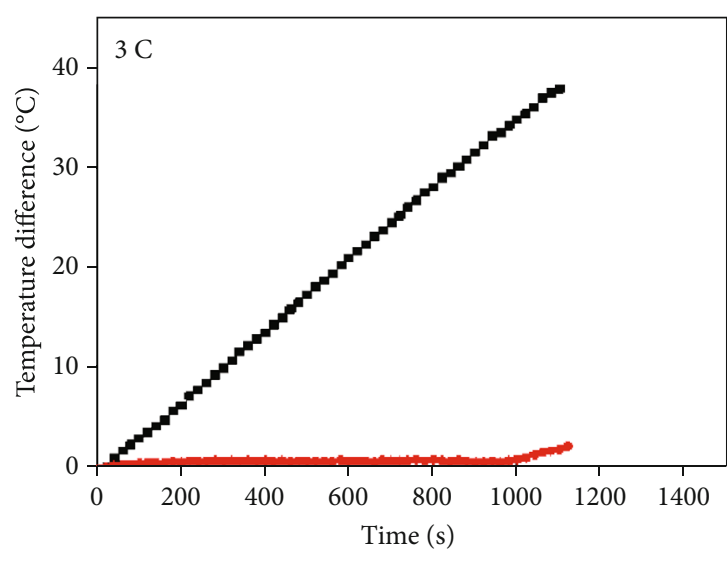

- $\mathrm{FC}$

- $\mathrm{PCM}+\mathrm{FC}$

(c)

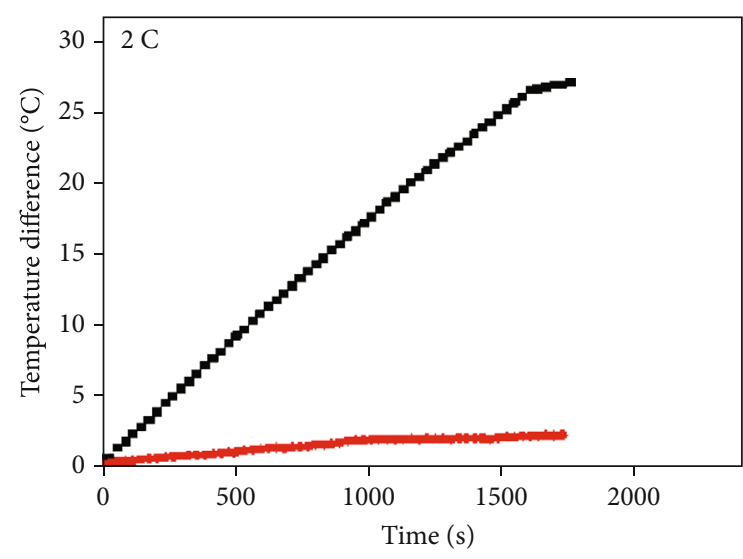

- $\mathrm{FC}$

- $\mathrm{PCM}+\mathrm{FC}$

(b)

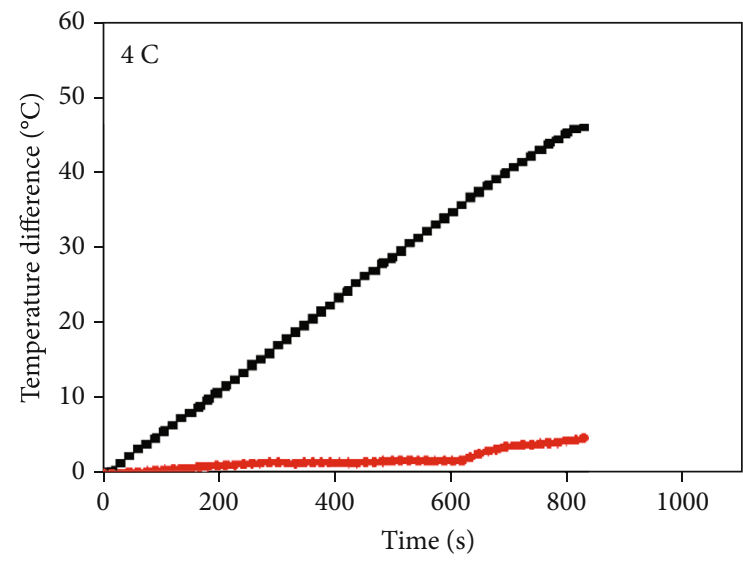

- $\mathrm{FC}$

- $\mathrm{PCM}+\mathrm{FC}$

(d)

FIGURE 11: Temperature consistency comparison of the battery modules with different cooling media $(3 \mathrm{~m} / \mathrm{s})$.

PCM. When the PA, ER, and EG contents are $50 \%, 47 \%$, and $3 \%$, the three mechanical properties exhibited optimum values.

The PCM with good mechanical properties can provide good protection for the battery. The bending and tensile strength of PCM can be improved by adding ER. Therefore, in order to adapt to the practical application process, it is necessary to adjust the correct proportion of PA and ER to make the composite PCM have good latent heat value and mechanical properties.

3.4. Thermal Management Analysis of Battery Modules with Different Heat Dissipation Schemes. The peak temperature and consistency are regarded as fundamental technical parameters considering heat generation and thermal safety. Figure 10 demonstrates that the peak temperatures of the PCM coupled with the FC system decreased to $40.1^{\circ} \mathrm{C}, 47.4^{\circ} \mathrm{C}, 53.4^{\circ} \mathrm{C}$, and $63.2^{\circ} \mathrm{C}$, thereby showing recession rates of $12.3 \%, 21.4 \%$, $31.2 \%$, and $31.3 \%$ compared with those of the air forced convection thermal management system when the discharge rates were $1,2,3$, and $4 \mathrm{C}$, respectively. The curves of the tempera- ture rise of the PCM coupled with the FC cooling system were smoother and gentler as the discharge current increased compared with those of a single air FC scheme, thereby indicating a low temperature ascending gradient and heat generation rate. When the peak temperature reaches $45^{\circ} \mathrm{C}$, the temperature rise rate of the $\mathrm{PCM}+\mathrm{FC}$ module will decrease. This is precisely because the PCM starts to work, which can absorb the heat of the battery and effectively reduce the temperature rise rate of the battery. The temperature distribution will be discussed and analyzed later.

Compared with the single FC cooling system, the PCM + FC cooling system can achieve more efficient cooling efficiency. Even during the high rate discharge process, the maximum temperature of the PCM+FC battery module is about $25^{\circ} \mathrm{C}$ lower than that of the FC battery module. This reflects that the cooling effect of the PCM+FC cooling system is more suitable for the conditions of the battery module at a high discharge rate.

3.5. Temperature Uniformity Study of the Battery Modules with Various Thermal Management Systems. To evaluate 
temperature uniformity, the maximum temperature difference of the ITMS $(3 \mathrm{~m} / \mathrm{s})$ and FC cooling system $(3 \mathrm{~m} / \mathrm{s})$ was studied at four discharge rates (Figure 11). The temperature uniformity of the two modules deteriorated with time. The maximum temperature difference of the IMTS with $3 \mathrm{~m} / \mathrm{s}$ was the minimum among these cases, thereby showing that the IMTS balanced the temperature in the battery more efficiently. The battery module containing the composite PCM with a $3 \mathrm{~m} / \mathrm{s}$ airflow rate exhibited a small, gradual decrease. This phenomenon is attributed to the composite PCM absorbing a large number of heat generated by the batteries utilizing the autologous latent heat during the liquidsolid phase transition process, controlling the peak temperature, and balancing the temperature difference between the batteries in the modules. The thermal conductivity of the composite PCM largely decreased when it reached or exceeded the thermal saturation state, thereby hindering heat dissipation and causing the temperature difference to ascend slowly during the rest of the period. Consequently, the PCM coupling FC cooling system for thermal management exhibited optimum control and stretched the temperature capacity regardless of the constant current discharge condition or uninterrupted charge-discharge cycling operations, which is beneficial for the improvement of thermal safety performance and further increases service life in the practical industrial process.

For poor temperature consistency applicability of the FC cooling system, the PCM+FC cooling system can effectively solve this problem. The PCM can absorb the heat generated by each battery well, and the flow of air can improve the heat dissipation of PCM. It can be seen that the PCM+FC battery module can maintain good temperature consistency even under a high discharge rate.

\section{Conclusions}

In this paper, a novel ITMS with PCM coupled with forced air convection cooling has been proposed for large-scale Liion battery modules. The impact factors, including the airflow rate, different discharge rate, and PCM fraction, have been considered to optimize the temperature of the battery module. The main conclusions can be summarized as follows:

(1) The change of the airflow rate can mainly affect the cooling effectiveness of the battery module, and the optimum velocity was $3 \mathrm{~m} / \mathrm{s}$

(2) The numerical simulation has been validated with the experimental results, which were in good agreement for the BTMS with the air cooling system at 1 and $4 \mathrm{C}$ discharge rates

(3) The ITMS, including the PCM coupled with the air cooling system for the battery module, demonstrated excellent thermal management effectiveness at 1, 2, 3, and $4 \mathrm{C}$. The battery module at a $4 \mathrm{C}$ discharge rate can control the maximum temperature below $63.2^{\circ} \mathrm{C}$ and maintain the maximum temperature difference within $4.8^{\circ} \mathrm{C}$
Therefore, it should be concluded that the ITMS could promote the development of the thermal management for battery modules in practical application.

\section{Nomenclature}

C: $\quad$ Capacity $\left(\mathrm{J} \mathrm{kg}^{-1} \mathrm{~K}^{-1}\right)$

$C_{\mathrm{p}}: \quad$ Specific heat $\left(\mathrm{J} \mathrm{kg}^{-1} \mathrm{~K}^{-1}\right)$

$C_{\mathrm{p}, \mathrm{a}}$ : Specific heat of air $\left(\mathrm{J} \mathrm{kg}^{-1} \mathrm{~K}^{-1}\right)$

$k_{\mathrm{a}}$ : Thermal conductive coefficient of air $\left(\mathrm{W} \mathrm{m}^{-1} \mathrm{~K}^{-1}\right)$

$m$ : Mass $(\mathrm{kg})$

p: $\quad$ Pressure $(\mathrm{Pa})$

T: $\quad$ Temperature $\left({ }^{\circ} \mathrm{C}\right)$

$t$ : $\quad$ Time (s)

$T_{\mathrm{a}}$ : Temperature of air $\left({ }^{\circ} \mathrm{C}\right)$

$Q_{\mathrm{r}}$ : Reaction heat

$Q_{\mathrm{p}}$ : Polarization reaction heat

$Q_{\mathrm{s}}$ : Side reaction heat

$Q_{j}$ : Joule heat

\section{Acronyms}

ITMS: Integrated thermal management system

EVs: Electric vehicles

BTMS: Battery thermal management system

PCM: Phase change material

FC: $\quad$ Forced convection

\section{Greek Symbols}

$\mu$ : Dynamic viscosity (Pas)

$v$ : Velocity vector of air $\left(\mathrm{m} \mathrm{s}^{-1}\right)$

$\rho_{\mathrm{a}}$ : Density of air $\left(\mathrm{kg} \mathrm{m}^{-3}\right)$

$\rho:$ Density $\left(\mathrm{kg} \mathrm{m}^{-3}\right)$

\section{Data Availability}

The data are available upon requesting the corresponding author.

\section{Conflicts of Interest}

The authors declare that they have no conflicts of interest.

\section{Acknowledgments}

This work is supported by the National Natural Science Foundation of China (Grant No. 51803036), the Foshan City Science and Technology Innovation Project (No. 2017IT100143), the Guangzhou Science and Technology Plan Scientific Research Project (No. 201607010259), the Postdoctoral Science Foundation of China (No. 2017M622625), and the China Postdoctoral Science Foundation (Nos. 2018T111093 and 2018M643732).

\section{References}

[1] P. Qin, M. Liao, D. Zhang, Y. Liu, J. Sun, and Q. Wang, "Experimental and numerical study on a novel hybrid battery thermal 
management system integrated forced-air convection and phase change material," Energy Conversion and Management, vol. 195, pp. 1371-1381, 2019.

[2] D. Zou, X. Liu, R. He et al., "Preparation of a novel composite phase change material (PCM) and its locally enhanced heat transfer for power battery module," Energy Conversion and Management, vol. 180, pp. 1196-1202, 2019.

[3] X. Li, Q. Huang, J. Deng, G. Zhang, Z. Zhong, and F. He, "Evaluation of lithium battery thermal management using sealant made of boron nitride and silicone," Journal of Power Sources, vol. 451, article 227820, 2020.

[4] H. Liu, Z. Wei, W. He, and J. Zhao, "Thermal issues about Liion batteries and recent progress in battery thermal management systems: a review," Energy Conversion and Management, vol. 150, pp. 304-330, 2017.

[5] J. Kim, J. Oh, and H. Lee, "Review on battery thermal management system for electric vehicles," Applied Thermal Engineering, vol. 149, pp. 192-212, 2019.

[6] K. Chen, M. Song, W. Wei, and S. Wang, "Structure optimization of parallel air-cooled battery thermal management system with U-type flow for cooling efficiency improvement," Energy, vol. 145, pp. 603-613, 2018.

[7] Y. Fan, Y. Bao, C. Ling, Y. Chu, X. Tan, and S. Yang, "Experimental study on the thermal management performance of air cooling for high energy density cylindrical lithium-ion batteries," Applied Thermal Engineering, vol. 155, pp. 96-109, 2019.

[8] S. Panchal, R. Khasow, I. Dincer, M. Agelin-Chaab, R. Fraser, and M. Fowler, "Thermal design and simulation of minichannel cold plate for water cooled large sized prismatic lithium-ion battery," Applied Thermal Engineering, vol. 122, pp. 80-90, 2017.

[9] W. Yang, F. Zhou, H. Zhou, Q. Wang, and J. Kong, “Thermal performance of cylindrical lithium-ion battery thermal management system integrated with mini-channel liquid cooling and air cooling," Applied Thermal Engineering, vol. 175, p. 115331, 2020.

[10] D. Kong, R. Peng, P. Ping, J. du, G. Chen, and J. Wen, “A novel battery thermal management system coupling with PCM and optimized controllable liquid cooling for different ambient temperatures," Energy Conversion and Management, vol. 204, p. 112280, 2020.

[11] W. Cao, C. Zhao, Y. Wang, T. Dong, and F. Jiang, "Thermal modeling of full-size-scale cylindrical battery pack cooled by channeled liquid flow," International Journal of Heat and Mass Transfer, vol. 138, pp. 1178-1187, 2019.

[12] Q. Huang, X. Li, G. Zhang, J. Zhang, F. He, and Y. Li, "Experimental investigation of the thermal performance of heat pipe assisted phase change material for battery thermal management system," Applied Thermal Engineering, vol. 141, pp. 1092-1100, 2018.

[13] Z. Ling, W. Lin, Z. Zhang, and X. Fang, "Computationally efficient thermal network model and its application in optimization of battery thermal management system with phase change materials and long-term performance assessment," Applied Energy, vol. 259, article 114120, 2020.

[14] J. Zhang, X. Li, G. Zhang et al., "Characterization and experimental investigation of aluminum nitride-based composite phase change materials for battery thermal management," Energy Conversion and Management, vol. 204, article 112319, 2020.

[15] J. Liang, "Investigation on the thermal performance of a battery thermal management system using heat pipe under different ambient temperatures," Energy Conversion and Management, vol. 155, pp. 1-9, 2018.

[16] D. Dan, C. Yao, Y. Zhang, H. Zhang, Z. Zeng, and X. Xu, "Dynamic thermal behavior of micro heat pipe array-air cooling battery thermal management system based on thermal network model," Applied Thermal Engineering, vol. 162, p. 114183, 2019.

[17] H. Behi, D. Karimi, M. Behi et al., "A new concept of thermal management system in Li-ion battery using air cooling and heat pipe for electric vehicles," Applied Thermal Engineering, vol. 174, article 115280, 2020.

[18] Y. Xie, J. Tang, S. Shi et al., "Experimental and numerical investigation on integrated thermal management for lithiumion battery pack with composite phase change materials," Energy Conversion and Management, vol. 154, pp. 562-575, 2017.

[19] M.-S. Wu, K. H. Liu, Y. Y. Wang, and C. C. Wan, "Heat dissipation design for lithium-ion batteries," Journal of Power Sources, vol. 109, no. 1, pp. 160-166, 2002.

[20] S. Park and D. Jung, "Battery cell arrangement and heat transfer fluid effects on the parasitic power consumption and the cell temperature distribution in a hybrid electric vehicle," Journal of Power Sources, vol. 227, no. 4, pp. 191-198, 2013.

[21] W. Wu, S. Wang, W. Wu, K. Chen, S. Hong, and Y. Lai, "A critical review of battery thermal performance and liquid based battery thermal management," Energy Conversion and Management, vol. 182, pp. 262-281, 2019.

[22] A. de Vita, A. Maheshwari, M. Destro, M. Santarelli, and M. Carello, "Transient thermal analysis of a lithium-ion battery pack comparing different cooling solutions for automotive applications," Applied Energy, vol. 206, pp. 101-112, 2017.

[23] Y. Huo, Z. Rao, X. Liu, and J. Zhao, "Investigation of power battery thermal management by using mini-channel cold plate," Energy Conversion and Management, vol. 89, pp. 387395, 2015.

[24] Y. Chung and M. S. Kim, "Thermal analysis and pack level design of battery thermal management system with liquid cooling for electric vehicles," Energy Conversion and Management, vol. 196, pp. 105-116, 2019.

[25] Y. Huang, P. Mei, Y. Lu et al., “A novel approach for Lithiumion battery thermal management with streamline shape mini channel cooling plates," Applied Thermal Engineering, vol. 157, p. 113623, 2019.

[26] X. Li, D. Zhou, G. Zhang, C. Wang, R. Lin, and Z. Zhong, "Experimental investigation of the thermal performance of silicon cold plate for battery thermal management system," Applied Thermal Engineering, vol. 155, pp. 331-340, 2019.

[27] S. A. Hallaj and J. R. Selman, "A novel thermal management system for electric vehicle batteries using phase-change material," Journal of the Electrochemical Society, vol. 147, no. 9, p. 3231, 2000.

[28] L. Zhang, K. Zhou, Q. Wei et al., "Thermal conductivity enhancement of phase change materials with $3 \mathrm{D}$ porous diamond foam for thermal energy storage," Applied Energy, vol. 233-234, pp. 208-219, 2019.

[29] Z. Lei, Z. Maotao, X. Xiaoming, and G. Junkui, “Thermal runaway characteristics on NCM lithium-ion batteries triggered by local heating under different heat dissipation conditions," Applied Thermal Engineering, vol. 159, article 113847, 2019.

[30] S. Wilke, B. Schweitzer, S. Khateeb, and S. al-Hallaj, "Preventing thermal runaway propagation in lithium ion battery packs 
using a phase change composite material: an experimental study," Journal of Power Sources, vol. 340, pp. 51-59, 2017.

[31] M. Alipanah and X. Li, "Numerical studies of lithium-ion battery thermal management systems using phase change materials and metal foams," International Journal of Heat and Mass Transfer, vol. 102, pp. 1159-1168, 2016.

[32] Y. Azizi and S. M. Sadrameli, "Thermal management of a $\mathrm{LiFePO}_{4}$, battery pack at high temperature environment using a composite of phase change materials and aluminum wire mesh plates," Energy Conversion and Management, vol. 128, pp. 294-302, 2016.

[33] M. Pan and Y. Zhong, "Experimental and numerical investigation of a thermal management system for a Li-ion battery pack using cutting copper fiber sintered skeleton/paraffin composite phase change materials," International Journal of Heat and Mass Transfer, vol. 126, pp. 531-543, 2018.

[34] M. Li, J. Liu, and J. Shi, "Synthesis and properties of phase change microcapsule with $\mathrm{SiO}_{2}-\mathrm{TiO}_{2}$, hybrid shell," Solar Energy, vol. 167, pp. 158-164, 2018.

[35] Y. Lv, D. Zhou, X. Yang, X. Liu, X. Li, and G. Zhang, "Experimental investigation on a novel liquid-cooling strategy by coupling with graphene-modified silica gel for the thermal management of cylindrical battery," Applied Thermal Engineering, vol. 159, p. 113885, 2019.

[36] B. Mortazavi, H. Yang, F. Mohebbi, G. Cuniberti, and T. Rabczuk, "Graphene or h-BN paraffin composite structures for the thermal management of Li-ion batteries: a multiscale investigation," Applied Energy, vol. 202, pp. 323-334, 2017.

[37] T. Wang, Y. Jiang, J. Huang, and S. Wang, "High thermal conductive paraffin/calcium carbonate phase change microcapsules based composites with different carbon network," Applied Energy, vol. 218, pp. 184-191, 2018.

[38] M. Li and B. Mu, "Effect of different dimensional carbon materials on the properties and application of phase change materials: a review," Applied Energy, vol. 242, pp. 695-715, 2019.

[39] Z. Ling, J. Chen, X. Fang et al., "Experimental and numerical investigation of the application of phase change materials in a simulative power batteries thermal management system," Applied Energy, vol. 121, no. 121, pp. 104-113, 2014.

[40] H. Fathabadi, "High thermal performance lithium-ion battery pack including hybrid active-passive thermal management system for using in hybrid/electric vehicles," Energy, vol. 70, no. 3, pp. 529-538, 2014.

[41] W. Wu, X. Yang, G. Zhang et al., “An experimental study of thermal management system using copper mesh-enhanced composite phase change materials for power battery pack," Energy, vol. 113, pp. 909-916, 2016.

[42] W. Wu, X. Yang, G. Zhang, K. Chen, and S. Wang, "Experimental investigation on the thermal performance of heat pipe-assisted phase change material based battery thermal management system," Energy Conversion and Management, vol. 138, pp. 486-492, 2017.

[43] G. Jiang, J. Huang, M. Liu, and M. Cao, "Experiment and simulation of thermal management for a tube-shell Li-ion battery pack with composite phase change material," Applied Thermal Engineering, vol. 120, pp. 1-9, 2017.

[44] A. Lazrak, J. F. Fourmigué, and J. F. Robin, “An innovative practical battery thermal management system based on phase change materials: numerical and experimental investigations," Applied Thermal Engineering, vol. 128, pp. 20-32, 2018.
[45] W. Wu, J. Liu, M. Liu et al., "An innovative battery thermal management with thermally induced flexible phase change material," Energy Conversion and Management, vol. 221, article 113145, 2020.

[46] Z. Qian, Y. Li, and Z. Rao, "Thermal performance of lithiumion battery thermal management system by using minichannel cooling," Energy Conversion and Management, vol. 103, pp. 157-165, 2016. 